\title{
Two case reports of possible noise trauma after inflation of air bags in low speed car crashes
}

\author{
Graham Buckley, Nicholas Setchfield, Richard Frampton
}

Air bags have contributed substantially to the safety of car occupants in road accidents, but concern exists that they may inflate unnecessarily in low speed crashes. ${ }^{1}$ Previous articles have reported eye, face, upper limb, and chest injuries caused by air bag inflation. ${ }^{2}$ Despite the high noise level generated by the bags on inflation, we are aware of only one paper reporting that air bag inflation might induce hearing loss. ${ }^{3}$ We describe two cases of hearing loss and persistent tinnitus that may have resulted from air bag inflation in low speed collisions. Neither subject sustained other injuries. Audiometry results are shown in the figure.

\section{Case reports}

Case 1-A 38 year old woman was in a collision in the United States while driving at about 20 miles an hour $(32 \mathrm{~km} / \mathrm{h})$. The air bag struck her on the right side of the face. She noticed an immediate bilateral hearing loss and tinnitus. She also had unsteadiness, which lasted 2 weeks. The hearing on the left improved over the next 5 days but on the right remained impaired and was accompanied by mild, persistent tinnitus. She had noticed no prior hearing loss and had no history of serious illness. Examination was normal, and audiometry showed a bilateral, high frequency, sensorineural hearing loss-much worse in the right ear.

Case 2-A 68 year old man drove into the back of another vehicle at about $15 \mathrm{mph}$. The air bag inflated, and he noticed an immediate bilateral hearing loss and tinnitus. He had no history of serious illness except hyperlipidaemia, which was being treated. Examination was normal, and audiometry showed a bilateral, sensorineural hearing loss. His hearing had been tested 18 months earlier as part of a health screen, and the audiogram was available.

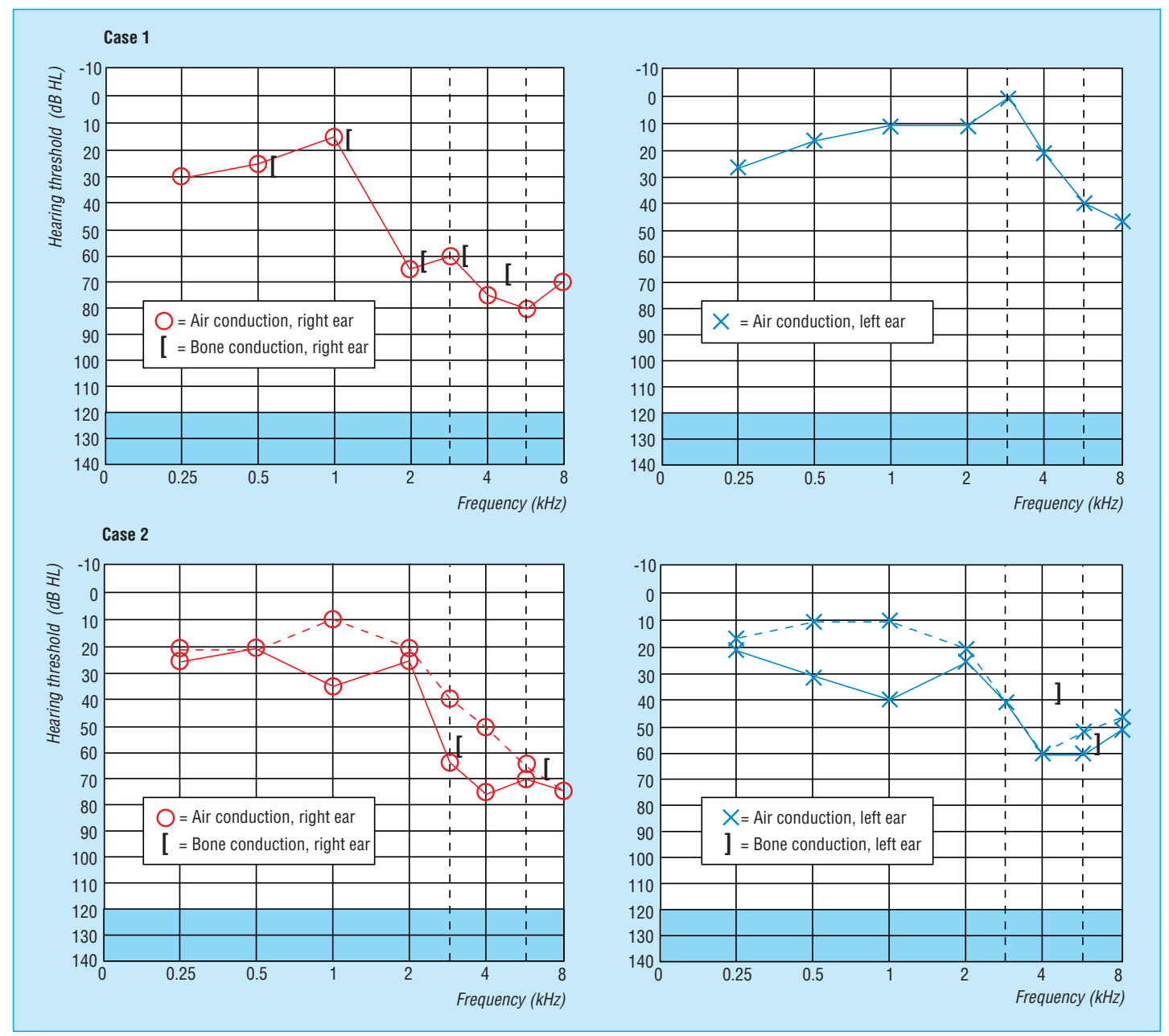

Audiograms for subjects in both cases (pre-exposure thresholds are shown in dotted line for case 2)

Department of Otolaryngology (Head and Neck

Surgery), St James's University Hospital, Leeds LS9 7TF

Graham Buckley, consultant otolaryngologist

Department of Audiology,

St James's

University Hospital

Nicholas Setchfield, chief audiologist

Vehicle Safety Research Centre, Loughborough, Leicestershire LE11 3UZ

Richard Frampton, principal consultant

Correspondence to: Mr Buckley jgrahambuckley@ compuserve.com

BMJ 1999;318:499-500 


\section{Comment}

The pre-injury hearing level in case 1 is unknown, but the pattern of the hearing loss, its severity in a woman of this age, and her apparently previously normal hearing strongly suggest a causal link. In case 2 , the subject had a pre-existing hearing loss, but his hearing deteriorated substantially in the right ear-at $1 \mathrm{kHz}$ and in the higher frequencies. Alteration of hearing at $1 \mathrm{kHz}$ is unusual but recognised after noise trauma. Both subjects perceived an immediate threshold shift, which decreased in severity with time and so was not as great by the time audiometry was performed.

The inflation of an air bag is triggered by vehicle deceleration and can generate a sound pressure level of $150-170 \mathrm{~dB}$ in $<100 \mathrm{~ms}^{4}$ The level depends on the size of car, number of occupants, ventilation, size and number of air bags, and inflation rate. In a study of the effect of air bag "slap" on the ears of squirrel monkeys, the researchers found no permanent hearing damage, ear drum perforation, or disruption of ossicles in air bag velocities of up to $100 \mathrm{mph}$ with a sound pressure level on inflation of $150 \mathrm{~dB} .^{5}$ None the less, this level might cause acoustic trauma in some humans. Cochlear damage may arise from the effects of noise or blast injury. The likelihood of damage depends on the noise level, the exposure time, and individual sensitivity.

Injury from air bags may be more likely in the future. Current safety design is moving towards vehicles with air bags that inflate in frontal and side crashes for both front seat positions. Lack of space means that side air bags inflate very quickly and are closer to the ear.

It is surprising that hearing loss is not reported more frequently after air bag inflation. Any loss identified is perhaps ascribed to other factors associated with a car accident. Also, in an accident the victim is unlikely to register and remember the noise of the air bag. It is therefore unclear whether these cases are isolated or represent a more widespread occurrence.

Contributors: GB had the original idea, NS advised on and carried out the audiometric testing, and RF provided information on air bag construction and literature on testing. The paper was jointly written by all three authors. GB will act as guarantor.

Funding: None.

Competing interests: None declared.

1 Third report to Congress. Effectiveness of occupant protection systems and their use (http://www.nhtsa.dotgov:80/cars/rules/rulings/208con2e html).

2 Antosia RE, Partridge RA, Virk AS. Air bag safety. Ann Emerg Med 1995;25:794-8.

3 Saunders JE. Slattery WH III, Luxford WM. Automobile airbag impulse noise: otologic symptoms in six patients. Otolaryngol Head Neck Surg 1998:118:228-34

4 Rouhana SW, Webb SR, Wooley RG, McCleary JD, Wood FD, Salva DB. Investigation into the noise associated with air bag deployment. Part 1. Measurement technique and parameter study. Warrendale, PA: Society of Automotive Engineers, 1994. (Report 942218.)

5 Richter HJ II, Stalnaker RL, Pugh JE Jr. Otologic hazards of airbag restraint system. Society for Automotive Engineers, 1974. (Paper No 741185; can be ordered through the SAE at www.sae.org.)

(Accepted 23 October 1998)

\title{
Questionnaire survey of advice given to patients with fractures
}

\author{
Badal Pal
}

Editorial by Doube

South Manchester

University Hospitals

NHS Trust,

Withington

Hospital, West

Didsbury

Manchester

M20 2LR

Badal Pal,

consultant

rheumatologist

bpal@fs1.with.man. ac.uk

BMJ 1999;318:500-
Osteoporosis, which contributes to some 150000 fractures annually, cost the NHS $£ 750$ million in $1994,{ }^{1}$ and current estimates exceed this figure. Department of Health guidelines on osteoporosis published in November $1994^{1}$ recommend an aggressive approach, even in patients with established osteoporosis. Guidelines from the Royal College of Physicians also exist with regard to aspects of rehabilitation in fracture management. ${ }^{2}$ What advice (relating especially to rehabilitation as well as assessment and treatment of osteoporosis) patients with fractured hip and vertebrae actually receive is not known.

\section{Patients, methods, and results}

Names and addresses of 96 patients with recent fractures were obtained (in the latter part of 1996) from 56 hospital based orthopaedic surgeons in the Greater Manchester area (out of 70 contacted) who each selected up to two patients at random; 14 further names were obtained through announcements in the local evening newspaper. A detailed questionnaire seeking information on advice and treatment was mailed to these 110 patients; 82 completed questionnaires were returned (response 74.5\%). Most patients were retired. Past occupations were mainly sedentary, and 19 of the women were housewives.

Awareness of osteoporosis as brittle bone disease and its risks was reported by 34 patients. Sources of this knowledge were doctors in only 10 and the media or friends or relatives in the rest. Most patients (61) were discharged home directly from the orthopaedic ward, but a smaller number (8) required a further period of rehabilitation in the geriatric or rehabilitation ward before discharge (13 patients did not answer this question). Other important findings are given in the table.

\section{Comment}

Patients with fracture have limited knowledge and awareness of osteoporosis, and the information that they do have seems to come mainly from the media rather than from professionals. Orthopaedic surgeons apparently do not place much importance on lifestyle factors such as smoking or excess alcohol consumption in their dealings with patients with fracture. A greater emphasis needs to be placed on public health education in general and specifically in patients who have already suffered a fracture. 